\title{
Accessibility to Oral Health Care in Peri-Urban Areas of Burkina Faso: Qualitative Survey on the Perceptions of the Populations of Kaya Health District
}

\author{
Drabo Rose ${ }^{1}$, Sangaré Abou Dramane ${ }^{2, ~ *, ~ S a m b a ~ M a m a d o u ², ~ G u i n a n ~ J e a n ~ C l a u d e ~}{ }^{2}$ \\ ${ }^{1}$ Directorate for Prevention and Control of Non-Communicable Diseases, Ministry of Health, Ouagadougou, Burkina Faso \\ ${ }^{2}$ Department of Public Health, UFR of Odonto-Stomatology, Felix Houphouet-Boigny, Abidjan, Côte d'Ivoire
}

Email address:

sangare_aboudramane@yahoo.fr (S. A. Dramane)

${ }^{*}$ Corresponding author

To cite this article:

Drabo Rose, Sangaré Abou Dramane, Samba Mamadou, Guinan Jean Claude. Accessibility to Oral Health Care in Peri-Urban Areas of Burkina Faso: Qualitative Survey on the Perceptions of the Populations of Kaya Health District. World Journal of Public Health. Vol. 4, No. 1, 2019, pp. 20-23. doi: 10.11648/j.wjph.20190401.13

Received: March 15, 2019; Accepted: April 16, 2019; Published: May 15, 2019

\begin{abstract}
Accessibility to oral health care in the sub-urban areas is a case for worry due to scarcity of basic socio-sanitary facilities in these zones. The purpose of this study was to understand the perceptions of peri-urban dwellers about the use of oral health services. The nature of this quality study centres on people of eighteen years and above who came to the Regional Medical Centre of Kaya for oral health care purposes. The trial case comprised of thirty individuals divided into three focal groups of ten people each. The data were assembled as a support paper following the guide line elaborated for the purposes of the study, and analyzed according to the methods of content analysis. The study has revealed that oral health care services are not very much available in the peri-urban areas of the District of Kaya. The inhabitants are confronted with financial, geographic and cultural handicaps which impacts negatively on their oral health care. The inhabitants, most of whom are, farmers without a stable source of revenue, tend to resort to traditional remedies as solutions to their oral/dental diseases. This work has brought to focus the factors that impede attendance to oral health care by the inhabitants of peri-urban communities of the District of Kaya. Improving the use of the oral health care services entails improving the basic social facilities of the rural people as well as improving the condition of living in their territories.
\end{abstract}

Keywords: Accessibility, Oral Health Care, Perception, Recourse, Burkina Faso

\section{Introduction}

The objective of every health care policy is to carter for the entire health problems of the people, including the rural, urban and sub-urban inhabitants, with the single aim of improving their overall living condition. However, in developing countries, a sub-urban area, a zone of transition between the township and the village, set up in the context of unplanned rapid urbanization, is faced with numerous problems [1]. A place of high population density with the people often living in precarious conditions, this place lacks basic health equipment unlike the urban areas that are better equipped and better staffed. The majority of the inhabitants are composed of workers and the youths tend to adopt certain urban ways of life. This situation exposes them to factors that increase the risks of chronic oral infections in accordance with their ways of life such as consumption of alcohol, of tobacco and of foods rich in sugar content [2]. This correlation between the conditions of living of the people and their oral health needs and expectations has been clearly emphasized by numerous studies [3, 4]. The problems exist, mainly, in relation to the availability and their use to better the health of the population living in sub-urban areas.

However, in sub-Saharan Africa, a lot of studies have been carried out on the question of the problems relating to accessibility to oral health care in the sub-urban communities [5-7]. The principal question centering on the inhabitants of the semi-urban communities, where the basic health facilities do not function well, is not adequately addressed. At the same time, we tend to live in an age where rapid urbanization 
that is pushed, more and more, to greater heights in most developing countries such as Burkina Faso is encouraged, where semi-urban area occupies a vital place. Also, the question of access to oral health care on the part of the people living in these zones becomes an issue of concern. For a better understanding of the problem, and in a participative approach for an effective planning, it has seemed important to understand the idea which the natives themselves have about the oral health challenges in these zones under focus. This work, channeled to this dynamics, has as objective to understand the attitude of the inhabitants of semi-urban environs about their attendance to oral health care.

\section{Methods}

\subsection{Type and Area of the Study}

The work of this nature has as its a focal point the Health District of Kaya, among which is the Kaya township, the principal city of the North Central Region of Burkina Faso, located about $100 \mathrm{~km}$ from Ouagadougou, the capital city of Burkina Faso. This District has a public oral health structure located within the Regional Hospital of Kaya and a Private Professional Clinic. The health district has four health workers in dental surgery who take care of oral diseases with a failing technical platform.

\subsection{Study Population, Selection Criteria, Sample Size}

The study was conducted between February and March 2015. It concerned the patients received at the Dental Department of Kaya Regional Hospital for oral health-related cases. The sample for the study composed of 30 patients selected from among those who came to the Regional Hospital for medical consultation on oral health related problems and who met with the laid down criteria for the study which include: being at least 18 years of age at the time of the study; being a resident of a rural community within the North Central Region; being in a good mental condition, and being willing to participate in the study. A rural community is defined as a habitation zone situated close to but not part of a township.

\subsection{Data Collection and Variables Studied}

The data were collected based on 3 focal groups (young people below 30 years, men and women above 30 years) an interviewer assisted by a second person for note taking on a paper. The information collected centered on: attendance to oral health care centres by the natives; the assessment of the quality of the treatment dispensed in the health centre, the reasons for resorting to other forms of treatment other than that of the conventional ones and the expectations of the people with regard to oral health care services.

\subsection{Data Analysis}

The information collected was transcribed then analyzed according to the method of the content analysis which consisted of synthesizing the propositions of the participants with the view of extracting from them the common notions. The data were analyzed manually and presented word for word. Those interviewed clearly and freely indicated their consent to participate in the study. Moreover, the Ethics Committee for research on health issues of the Ministry of health as well as the Ministry of Scientific research and Innovation jointly gave their consent to undertake this study.

\section{Results}

\subsection{Geographical Accessibility to Oral Health Treatment}

With regard to the affordability of oral health care, the study has shown that lack of facilities for dental consultancy services for the people living in the semi-urban areas makes it difficult for them to receive treatment. According to one of the people interviewed, a male adult of about 50 years, "One has to travel $35 \mathrm{~km}$ from the Public Health Centre (Barsalgho) to get to the Regional Hospital (Kaya)". The poor road network in these areas makes affordability of health care services more herculean. In a similar vein, a woman of about 38 years said: "During the winter (cold) period it becomes a herculean battle for us to receive treatment; willpower alone is not sufficient. The roads are severed".

Once, in the dental consultancy centre, the people interviewed manifested some mixed feelings in their assessment of the quality of reception in the centre. A 42year-old man declared thus: "That day, I arrived at the Regional Hospital of Kaya at about 1 P.M. The health worker received me well. Above all, he treated me. The ailing tooth was extracted. I regained my health". Never the less, this assessment was not shared by others like this young lady aged 28 who opined thus: "My front tooth was aching. I came to the Kaya Regional Hospital for treatment. The doctor told me that he was going to extract it. I resented and he said this to me: 'Here we are the ones who treat'.

\subsection{Financial Affordability}

According to the surveys conducted, the people of the North Central Regional of Burkina Faso are in majority farmers without a stable source of revenue. The cost of oral health care seems too high for them which, in turn, render these treatments inaccessible to the people. The people in these rural communities do not have a functional social protection system. On this point, a young male adult of 25 years had this to say: "You have to pay the consultation fee, pay for the drugs prescribed, pay for the services rendered; what is more, you have to pay for your transportation and feeding if you have to stay up to afternoon time; this costs us a lot". Another person aged 32 who was interviewed said that: "In the oral health care centres, there is nothing that costs 1 dollar like in other health care structures".

\subsection{Socio-Cultural Accessibility}

With regard to the socio-cultural accessibility, for the 
inhabitants of the District of Kaya, oral diseases do not lead to death. Therefore, it does not necessitate going to hospital for consultation. One only needs to ease the pain. In line with this, a female interviewed confided in us that: "one "regin" tablet (an analgesic) costs less than $\$ 0.20$ to relieve dental pain, while at the health centre it takes much more money to be treated by the doctor. So we prefer to buy the drugs on the street and treat ourselves". The obstacles hindering the use of the oral health care services are directly linked to the spread of oral diseases among the population. Also, one of the patients questioned had this to say: "... The fluid from the rupture of the water bag of my pregnancy came up to my mouth. This fluid infested my teeth" (a patient of 34 years). Another patient, 37 years said: “... The constant heavy load on our heads, as we journey from our farms back to our homes, is the cause of our dental problems". For another person, "...In the village, tooth ache does not entail going to the health centre for treatment. The dental ache is not a serious illness. It does not lead to death. We use our traditional medicines which are within our reach". Added to the non-perception of the gravity of the oral infections by the people is their ignorance about the capacity of the sanitary apparatus to take care of them. The words of this patient justify this position: "We are peasants, we never know that at the health care centre, we can treat our teeth well”.

\subsection{Expectations of People at Improving the Accessibility to Oral Health Care Services}

The expectations of the survey are directed towards a better financial accessibility and an improvement on the geographical accessibility of the oral health care facilities. According to a female participant, in her 40s, "In dental offices, nothing is cheaper. In addition to the transportation you have to pay to get there, you have to pay everything. The Government should make the treatments affordable as much as possible by paying the poorest of the society more".

About geographical accessibility, a 48-year-old male resident of Korsimoro (a village located at the outskirts of the city of Kaya) complained in the following terms: "Korsimoro is a big town without oral/dental services. Further, in Boussouma (a town in the outskirts of Kaya), there is equally no oral treatment services; one needs to travel about $35 \mathrm{~km}$ to get to Kaya and to receive treatment. Hence, it is important to bring the facilities nearer to the people so as to minimise their financial burden".

\section{Discussion}

The present study on the recourse to oral health care by the natives living in the semi-urban areas of Burkina Faso sought to understand the position of the people on the oral health care system. To achieve this, it hinged itself on the quality research technic channeled towards deeply understanding personal experiences and clarifying some (aspects of) social phenomena such as health and illness. This type of study contributes to understand better the needs of the beneficiaries and of the service providers in the oral health care sector and to integrate these needs during the course of formulating the recommendations addressed to the administrators of the system [8]. The study has shown that the people have difficulties accessing oral health care services which translates into poor usage of the oral health services which remains low in our area of study where as many people complain of oral health problems. This low level in the use of oral health services is attributable to the difficulties of financial accessibility, geographic accessibility and to some socio-cultural adherence [9]. A research conducted in Seattle in 1993, indicated that age and cultural factors play a preponderant role in use of oral health care services [10]. More so, the distance of the oral health centres from the natives, the deplorable state of the roads are the many factors that hinder the use of oral health care services and in turn increase the cost of medical treatments in Burkina Faso, according to some studies. This position is corroborated elsewhere in Africa, in Tanzania, for example, by a study done in 2007 on the factors that favour adherence to traditional options. The study showed that out of 365 patients with age range of 15 and above, $43.8 \%$ use traditional treatments and this choice is justified by $25 \%$ of them citing financial constraints [11]. In Côte d'Ivoire, Sangare and al., in a work on the aversion to treatments showed that financial accessibility proved to be a big obstacle in the use of oral health care services by the people [12]. Moreover, the absence of a well packaged social protection system makes medical treatments in general and oral health treatment in particular expensive to some people due the fact that they consider their cost too high.

The reasons for waiving dental care are many and are not limited only to financial ones. The opinion of the natives on the usefulness of good health needs to be taken into account. In fact, in the Health District of Kaya, the gravity of the oral health diseases is not perceived by the natives. Many patients of different social statuses and professions put together think that oral health treatment is a luxury reserved only for people of high social status. In fact, a research realized in France on the evolution of consumption of oral health care and aversion to treatments indicated that oral health treatment is not a priority for the people [13]. Also, our study has shown that the persistence of some cultural considerations is a factor militating against the use of oral health care services and justifies the attachment of the natives to traditional treatments. This fact was equally underlined in a study carried out in 2007 on the harmony between what is offered and the needs in oral health care sector [14].

In our study, the majority of focus group participants reported that they very often used the traditional practitioner as a first line to obtain different types of decoctions as "painkillers". If these attitudes could be justified on the context of poverty, a study carried out among some immigrants of Ghana origin residing in Canada, the attachment of these people to traditional treatments was linked to their seeming effectiveness, as a habit, but also to the fact of the holistic nature of the traditional medicine [15]. Neither do the inhabitants of Kaya Health District of Burkina 
Faso take advantage of the information relative to free treatment of oral health infections by the health service system. Again, lack of sensitivity on the part of the health workers and the anchorage of the people to socio-cultural beliefs, encourage the non-utilization of the oral health care facilities, though in scarcity.

In fact, it is averred that, in India, the availability of an offer of a quality treatment weighs a significant influence on the consumption of oral health treatment [16]. The context of Burkina Faso, just like in many other developing countries, requires that the collaboration between the public health workers and the traditional practitioner be encouraged and structured to adapt to universal free treatment of the health problems of the people $[17,18]$.

\section{Conclusion}

This quality study, based on the perception of the people about the use of oral health care facilities, reveal their underutilization in the semi-urban zones of the North Central Region of Kaya in Burkina Faso. This under-utilization is attributable to both geographic and financial factors and to the persistence of some socio-cultural beliefs among the people. These fundamental data demand that fundamental studies be carried out in order to better understand the oral health conditions of the natives as well as the modalities for responding to treatments. Nevertheless, these preliminary results indicate that any strategy to improve the oral health status of Kaya health district residents, should take into account the prevention of oral diseases and land-use planning, so as to bring basic infrastructure of the people. In addition, the establishment of an effective information system based on integrated monitoring of oral diseases would help to better control the spread of major oral diseases for the well-being of the population.

\section{Ethical Considerations and Conflict of Interest}

The informed consent of the respondents was obtained prior to their participation in the study. The confidentiality of the data has been guaranteed. The authors declare no conflict of interest.

\section{References}

[1] Rebouha F. "Concentration of health facilities, challenges of mobility and difficulties on access to treatment in the metropolitan city of Oran". Territory in movement geographic developmental review $2007 . \quad \mathrm{http} / /$ journals. Openedition.org/tem/852; DOI: 10.4000/tem.852

[2] Petersen PE. The World Oral Health Report 2003: continuous improvement of oral health in the 21st century - the approach of the WHO Global Oral Health Programme. Community Dent Oral Epidemiol 2003; 31 (Suppl. 1): 3-23.
[3] Colussi CF, Calvo MCM. An evaluation model for oral health in primary care. Cad Saúde Pública 2011; 27 (9): 1731-45.

[4] Roncalli AG, Tsakos G, Sheiham A, de Souza GC, Watt RG. Social determinants of dental treatment needs in Brazilian adults. BMC Public Health. 2014; 14: 1097.

[5] Varenne B, Msellati P, Zoungrana C, Fournet F, Salem G. Reasons for attending dental-care services in Ouagadougou, Burkina Faso. Bull World Health Organ. 2005; 83 (9): 650-5.

[6] Sangaré AD, Samba M, Bourgeois D. Illness-related behaviour and socio-demographic determinants of oral health care use in Dabou, Côte d'Ivoire. Community Dent Health. 2012; 29 (1): 78-84.

[7] Lo CM, Diop M, Faye D, Kanouté A, Diouf M, Cissé D. The determinants of the use of oral health care services by consumers in West Africa - the case of Senegal. Science J Public Health. 2016; 4 (6): 445-450.

[8] Dumez H. Méthodologie de la recherche qualitative 2è édition. Les questions clés de la démarche compréhensive. Eds Vuibert 2016.

[9] Sangaré AD, Samba M, Meless GD, Guinan JC, Bakayoko-Ly $\mathrm{R}$, Bourgeois D. Regards croisés sur le recours aux soins bucco-dentaires modernes et traditionnels enCôte d'Ivoire. Rev. Col Odonto-Stomatol. Afr. Chir. Maxillo-fac. 2013, 20 (3): $5-11$.

[10] Kiyak HA. Age and culture: influences on oral health behaviour. Int Dent J. 1993; 43 (1): 9-16.

[11] Mbwambo ZH, Mahunnah RLA, Kayombo EJ. Traditional health practitioner and the scientist: bridging the gap in contemporary health research in Tanzania. Tanzan J Health Res. 2007; 9 (2): 115-120.

[12] Sangaré AD, Samba M, Guinan JC, Diouf M, Bakayoko-Ly R, Bourgeois D. Socio demographic factors associated with renunciation to oral care in Côte d'Ivoire. MOJ Public Health 2017, 6 (1): 00156.

[13] Mizrahi A, Mizrahi A. Evolution de la consommation buccodentaire et renoncement aux soins CREDES; http://www.irdes.fr/Publications/Rapports1993/rap1005.pdf.

[14] Gobert M, Artoisenet C, Roch I. Offre et besoins en soins dentaires Perspectives d'avenir. Rapp Synthèse Univ Cathol Louvain-Socio-Econ Santé. 2007; 1-30.

[15] Barimah KB, Van Teijlingen ER. The use of traditional medicine by Ghanaians in Canada. BMC Complement Altern Med. 2008; 8 (1): 30.

[16] Rao KD, Ryan M, Shroff Z, Vujicic M, Ramani S, Berman P. Rural clinician scarcity and job preferences of doctors and nurses in India: a discrete choice experiment. PloS One. 2013; 8 (12): e82984.

[17] Lawal FB, Taiwo JO, Oke GA. Factors influencing awareness and attendance of traditional oral health care practices by residents of a peri-urban community in Ibadan, Nigeria. Afr Health Sci. 2015; 15 (1): 233-239.

[18] Enwonwu CO. Societal expectations for oral health: response of the dental care system in Africa. J Public Health Dent. 1988; 48 (2): 84-93. 